\title{
Setting up child health and mortality prevention surveillance
}

\section{in Ethiopia [version 1; peer review: 1 approved, 1 approved}

\section{with reservations]}

Anna C. Seale 1-3, Nega Assefa (1D1,2, Lola Madrid (iD1,2, Stefanie Wittmann1, Hanan Abdurahman'², Nardos Teferi², Letta Gedefa², Alexander Mohamed², Natnael Debela², Tseyon Tesfaye ${ }^{2}$, Tigistu Samuel2, Mehret Dubale1, Hiwot Yigzaw², Eyoel Taye (iD)2, Workalemahu Bekele2, Caroline Ackley', Gutema Imana Keno2, Yosef Zegeye2, Zerihun Girma², Ketema Degefa2, Berhanu Damisse (id), Adugna Tadesse (iD2, Mohammed Aliyi2, Gurmu Feyissa², Yenenesh Tilahun², Getahun Wakwaya², Bizunesh Sintayehu², Getamesay Abayneh², Addisu Alemu (iD2, Emmanuel Azore1, Joe Oundo1, Zelalem T Mariam², Dadi Marami (iD2, Mulu Berihun2, Mussie Berhanu(i)2, Mahlet Mekonnen2, Andualem Alemayehu², Nana Sarkodie-Mensah', Shirine Voller (D1,3, Boniface Jibendi13,3, Abraham Aseffa (D) 4, Taye Balcha4, Robert F. Breiman (iD) 5cott F Dowell (D6, Asnake Worku7, Tsigereda Kifle7, Ebba Abate7, Yadeta Dessie2 ${ }^{2}$ J. Anthony G. Scott'1,3

\footnotetext{
${ }^{1}$ Epidemiology and Population Health, London School of Hygiene \& Tropical Medicine, London, UK

${ }^{2}$ Haramaya University, Oromia, Ethiopia

${ }^{3}$ KEMRI-Wellcome Trust Research Programme, Kilifi, 30, 80108, Kenya

${ }^{4}$ Armauer Hansen Research Institute, Addis Ababa, Ethiopia

${ }^{5}$ Emory Global Health Institute, Emory University, USA

${ }^{6}$ Bill \& Melinda Gates Foundation, Seattle, USA

${ }^{7}$ Ethiopian Public Health Institute, Addis Ababa, Ethiopia
}

V1 First published: 24 Nov 2021, 5:173

https://doi.org/10.12688/gatesopenres.13395.1

Latest published: 14 Feb 2022, 5:173

https://doi.org/10.12688/gatesopenres.13395.2

\section{Abstract}

Background: Mortality rates for children under five years of age, and stillbirth risks, remain high in parts of sub-Saharan Africa and South Asia. The Child Health and Mortality Prevention Surveillance (CHAMPS) network aims to ascertain causes of child death in high child mortality settings (>50 deaths/1000 live-births). We aimed to develop a "greenfield" site for CHAMPS, based in Harar and Kersa, in Eastern Ethiopia. This very high mortality setting (>100 deaths/1000 live-births in Kersa) had limited previous surveillance capacity, weak

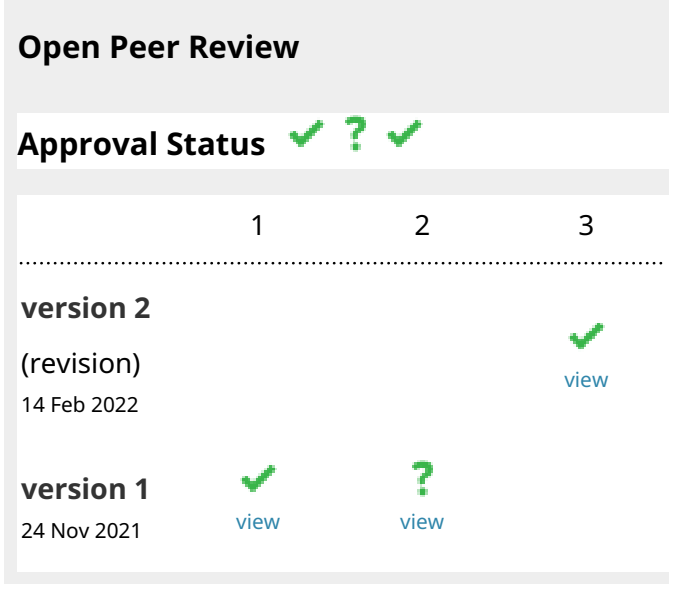


infrastructure and political instability. Here we describe site development, from conception in 2015 to the end of the first year of recruitment.

Methods: We formed a collaboration between Haramaya University and the London School of Hygiene \& Tropical Medicine and engaged community, national and international partners to support a new CHAMPS programme. We developed laboratory infrastructure and recruited and trained staff. We established project specific procedures to implement CHAMPS network protocols including; death notifications, clinical and demographic data collection, post-mortem minimally invasive tissue sampling, microbiology and pathology testing, and verbal autopsy. We convened an expert local panel to determine cause-of-death. In partnership with the Ethiopian Public Health Institute we developed strategies to improve child and maternal health.

Results: Despite considerable challenge, with financial support, personal commitment and effective partnership, we successfully initiated CHAMPS. One year into recruitment (February 2020), we had received 1173 unique death notifications, investigated 59/99 MITSeligible cases within the demographic surveillance site, and assigned an underlying and immediate cause of death to 53 children.

Conclusions: The most valuable data for global health policy are from high mortality settings, but initiating CHAMPS has required considerable resource. To further leverage this investment, we need strong local research capacity and to broaden the scientific remit. To support this, we have set up a new collaboration, the "Hararghe Health Research Partnership".

\section{Keywords}

surveillance, Ethiopia, mortality, deaths, child, infant, stillbirth, partnership

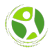

This article is included in the CHAMPS gateway.

1. Godfrey M. Bigogo, Kenya Medical Research Institute, Kisumu, Kenya

2. Bernt Lindtjørn (iD), Hawassa University, Hawassa, Ethiopia

University of Bergen, Bergen, Norway

3. Kobus Herbst (iD), Africa Health Research Institute, Somkhele, South Africa

Any reports and responses or comments on the article can be found at the end of the article. 


\section{Corresponding author: Anna C. Seale (anna.seale@warwick.ac.uk)}

Author roles: Seale AC: Conceptualization, Funding Acquisition, Investigation, Methodology, Writing - Original Draft Preparation; Assefa N: Conceptualization, Data Curation, Funding Acquisition, Investigation, Methodology, Supervision, Writing - Review \& Editing; Madrid L: Investigation, Methodology, Supervision, Writing - Review \& Editing; Wittmann S: Investigation, Methodology, Writing Review \& Editing; Abdurahman H: Investigation, Methodology, Writing - Review \& Editing; Teferi N: Investigation, Methodology, Writing - Review \& Editing; Gedefa L: Investigation, Methodology, Writing - Review \& Editing; Mohamed A: Investigation, Methodology, Writing - Review \& Editing; Debela N: Investigation, Methodology, Writing - Review \& Editing; Tesfaye T: Investigation, Methodology, Writing Review \& Editing; Samuel T: Investigation, Methodology, Writing - Review \& Editing; Dubale M: Investigation, Methodology, Writing Review \& Editing; Yigzaw H: Investigation, Methodology, Writing - Review \& Editing; Taye E: Investigation, Methodology, Writing Review \& Editing; Bekele W: Investigation, Methodology, Writing - Review \& Editing; Ackley C: Investigation, Methodology, Supervision, Writing - Review \& Editing; Keno GI: Investigation, Methodology, Writing - Review \& Editing; Zegeye Y: Investigation, Methodology, Writing - Review \& Editing; Girma Z: Investigation, Methodology, Writing - Review \& Editing; Degefa K: Investigation, Methodology, Writing - Review \& Editing; Damisse B: Investigation, Methodology, Writing - Review \& Editing; Tadesse A: Investigation, Methodology, Writing - Review \& Editing; Aliyi M: Investigation, Methodology, Writing - Review \& Editing; Feyissa G: Investigation, Methodology, Writing - Review \& Editing; Tilahun Y: Investigation, Methodology, Writing - Review \& Editing; Wakwaya G: Investigation, Methodology, Writing - Review \& Editing; Sintayehu B: Investigation, Methodology, Writing - Review \& Editing; Abayneh G: Investigation, Methodology, Writing - Review \& Editing; Alemu A: Investigation, Methodology, Writing - Review \& Editing; Azore E: Investigation, Methodology, Writing - Review \& Editing; Oundo J: Investigation, Methodology, Writing - Review \& Editing; Mariam ZT: Investigation, Methodology, Writing - Review \& Editing; Marami D: Investigation, Methodology, Supervision, Writing - Review \& Editing; Berihun M: Investigation, Methodology, Writing - Review \& Editing; Berhanu M: Investigation, Methodology, Writing - Review \& Editing; Mekonnen M: Investigation, Project Administration, Writing - Review \& Editing; Alemayehu A: Investigation, Methodology, Writing - Review \& Editing; Sarkodie-Mensah N: Investigation, Methodology, Writing - Review \& Editing; Voller S: Investigation, Methodology, Project Administration, Supervision, Writing - Review \& Editing; Jibendi B: Investigation, Methodology, Writing - Review \& Editing; Aseffa A: Conceptualization, Investigation, Methodology, Writing - Review \& Editing; Balcha T: Conceptualization, Investigation, Methodology, Writing - Review \& Editing; F. Breiman R: Conceptualization, Funding Acquisition, Investigation, Methodology, Supervision, Writing Review \& Editing; Dowell SF: Conceptualization, Funding Acquisition, Investigation, Methodology, Supervision, Writing - Review \& Editing; Worku A: Investigation, Methodology, Writing - Review \& Editing; Kifle T: Conceptualization, Investigation, Methodology, Supervision, Writing - Review \& Editing; Abate E: Conceptualization, Investigation, Methodology, Supervision, Writing - Review \& Editing; Dessie Y: Conceptualization, Funding Acquisition, Investigation, Methodology, Writing - Review \& Editing; Scott JAG: Conceptualization, Funding Acquisition, Investigation, Methodology, Supervision, Writing - Original Draft Preparation

Competing interests: No competing interests were disclosed.

Grant information: This work is supported by Emory University, funded by The Bill and Melinda Gates Foundation (INV-009109). ACS and JAGS are funded by The Wellcome Trust (205184 and 214320).

Copyright: (C) 2021 Seale AC et al. This is an open access article distributed under the terms of the Creative Commons Attribution License , which permits unrestricted use, distribution, and reproduction in any medium, provided the original work is properly cited.

How to cite this article: Seale AC, Assefa N, Madrid L et al. Setting up child health and mortality prevention surveillance in Ethiopia [version 1; peer review: 1 approved, 1 approved with reservations] Gates Open Research 2021, 5:173 https://doi.org/10.12688/gatesopenres.13395.1

First published: 24 Nov 2021, 5:173 https://doi.org/10.12688/gatesopenres.13395.1 


\section{Introduction}

Child survival has improved in recent years ${ }^{1}$. However, great inequalities remain worldwide and child mortality is disproportionately high in sub-Saharan Africa and South Asia. Causes attributed to deaths are often non-specific and, despite large studies $^{2-4}$, the infectious causes of severe disease and death have not been fully established. To accelerate progress, we need a comprehensive understanding of cause-specific mortality to direct public health interventions. The Child Health and Mortality Prevention Surveillance (CHAMPS) network was initiated to describe the causes of child mortality (under-5 years) and stillbirth, in sites in sub-Saharan Africa and South Asia through population-based surveillance, clinical data, verbal autopsy, and advanced post-mortem diagnostic approaches, including minimally invasive tissue sampling (MITS) ${ }^{5}$. Based on more comprehensive data, expert panels are able to determine the most likely underlying, co-morbid and immediate conditions leading to each death. Implementing this requires expertise and infrastructure to support community engagement, rapid notification of deaths, and detailed pathological investigation.

Ethiopia is the most populous landlocked country in the world, with a population of $108,000,000$ (July 2018) ${ }^{6}$. Despite reductions since the conception of the study, overall under five child mortality is still 55/1000 live births ${ }^{7}$, representing 181,250 deaths in 2019, and Ethiopia had the fifth highest number of stillbirths in the world $(97,000)$ in $2016^{8,9}$. Given the burden of mortality, including Ethiopia within the CHAMPS network provided an important opportunity to better understand child deaths. Emory University, which leads the CHAMPS network, requested applications for potential sites across sub-Saharan African and Asian countries. However, there was no location with existing capacity for all CHAMPS activities in Ethiopia. A CHAMPS presence would depend on creating capacity at a new or so-called "greenfield" site. The London School of Hygiene \& Tropical Medicine (LSHTM) was commissioned by the Bill \& Melinda Gates Foundation (BMGF) to investigate options, following a request from Emory University.

A small team from LSHTM visited Ethiopia in June and August 2015 , engaging with national stakeholders, to assess support for the initiative and explore potential partnerships. We also visited universities and their demographic surveillance systems (DSS), selected based on their mortality data; we aimed to visit DSSs with an under-5 child mortality rate (U5MR) of $>50 / 1000$ live births in the $2-5$ years prior to the visit ${ }^{10}$.

From these visits, we reported information on five potential locations back to Emory University and BMGF, comparing our findings against specific selection criteria. We also included considerations shared by national stakeholders; for example, representatives of the Federal Ministry of Health suggested recently established DSS sites could offer more opportunities for CHAMPS to study in a new area which had not included people studied for some time. Amongst the DSSs visited, only Kersa had a sufficient population size $(>100,000$ with $>3000$ births/year and $>12,000$ children under-5 years) to be included in CHAMPS. An additional advantage was the potential of including
Harar DSS, an area of urban surveillance encompassing Hiwot Fana Specialized University Hospital (HFSUH), the regional referral hospital in Harar. Kersa was an emerging DSS which had been set up and expanded more recently, and demonstrated a well-organised DSS platform with readily available data. Emory University and BMGF reviewed the report and recommendations and a representative from BMGF visited the proposed site. Finally, Kersa/Harar was selected and confirmed as the most suitable location. We describe the initiation and development of the CHAMPS site in Ethiopia below.

\section{Methods}

Site specifics

Country. Ethiopia is landlocked covering 1,104,300 $\mathrm{km}^{2}$ in the horn of Africa, with borders to Eritrea, Somalia, Kenya, South Sudan, and Sudan. It has ten regional states and two selfgoverning administrative cities, Adis Abeba (Addis Ababa) and Dire Dawa ${ }^{11}$. Ethiopia was ruled by a Monarchy until 1974 when the Derg (military council) deposed Emperor Haile Selassie. The Ethiopian People's Revolutionary Democratic Front took power in 1991. In recent times there has been intermittent instability, with states of emergency declared between 2016 and 2019. Despite this, Ethiopia has the fastest growing economy in the region (averaging 9.9\% per year from 2007/08 to 2017/18), attributed to increases in construction and services. However, the economy is predominantly agricultural, with a per capita income of $\$ 790$ and a quarter of the population living in poverty $(2016)^{6}$. Ethiopia is multi-cultural and multi-ethnic; the major religions are the Ethiopian Orthodox church (44\%) and Islam $(34 \%)^{11}$.

Site general characteristics. CHAMPS in Ethiopia is based in Harar (urban) and Kersa (rural). Harar is on a hilltop $(1885 \mathrm{~m})$ around $500 \mathrm{~km}$ from Addis Ababa. Harar is the capital of East Hararghe, a zone of Oromia Region, and the capital of the Harari Peoples Regional state, a small independent city region. Kersa is a rural district around $44 \mathrm{~km}$ from Harar. The district population is around 173,000 (2007 census), of whom $6.9 \%$ live in towns; the population density is low (372 people $\left./ \mathrm{km}^{2}\right)^{10}$. Kersa contains highlands and lowlands, and the area is semi-arid and prone to drought, with scarcity of food production. In rural areas water is sourced from springs and wells; there is no supply of electricity. The towns have water mains and are supplied with electricity, but both are frequently interrupted, often up to weeks at a time. There is farming in two seasons -- Kiremt or Meher (June to August) and Belg (Septemberto November)-- of wheat, barley and vegetables in the highlands; sorghum, maize and potatoes are farmed in the lowlands. Khat, a stimulant, is the dominant cash crop.

Demographic Surveillance. Kersa Health and Demographic Surveillance System (HDSS) was established in September $2007^{10}$, including 12 Kebeles (10 rural and two within small towns), the smallest administrative units in Ethiopia (Figure 1). In 2008, the HDSS catchment covered 50,607 person-years; since then 12 Kebeles have been added, for a total of 136,505 person years in 2019 . Under-5 child mortality is high at 58-170/1000 live births (Table 1). Harar HDSS was set 




Figure 1. Harar, Kersa and Haramaya Demographic Surveillance Sites (DSS) are within East Hararghe, Oromia, Ethiopia.

up in 2012, covering six Kebeles (all urban). In 2019 it covered 58,095 person-years, and under-5 child mortality was reported to be low at 5-20/1000 live births, Table 2. After the initiation of CHAMPS, an additional HDSS, Haramaya HDSS, was set up and enumerated in 2019.

Main diseases endemic in the area, according to previous surveillance or research. Despite high mortality in Kersa, there were no prior comprehensive studies of the causes of severe illness in children either in hospital or in the community ${ }^{12}$, and cause of death data were from verbal autopsy alone. Verbal autopsy data suggested that severe malnutrition, gastro-intestinal disease and acute lower respiratory tract infections were the leading causes of deaths in children (5-14 years, 2008-13) $)^{13}$, and sepsis, birth asphyxia and prematurity were leading causes in neonates (0-27 days) ${ }^{12}$. Malnutrition, diarrhoea and outbreaks of cholera and vaccine preventable diseases, such as measles, are common. A mini demographic and health survey for Ethiopia estimated $19 \%$ of children (12-23 months) had not had any vaccines in $2019^{7}$.

\section{Research capacity in the site}

Existing capacity

Haramaya University (HU) was set up in 1954 as a University of Agriculture in a large rural campus between Harar and $\mathrm{Kersa}^{10}$. HU now has a range of education programmes including College of Health and Medical Sciences campus in Harar, established in 1996. Academic staff from HU and Hiwot Fana Specialized University Hospital (HFSUH) contribute to CHAMPS from a range of disciplines, including demography, social science, microbiology, pathology, paediatrics and obstetrics.

Ethiopia has primary, secondary and tertiary levels of health care. Primary care includes health posts and health centres, with each health post serving 3000-5000 people ${ }^{14}$. Two health extension workers are assigned to each health post to link into the community. Around five health posts work with a health centre, which serves around 25,000 people $^{14}$. Within Kersa HDSS there are currently 19 health posts and six health centres. Secondary care is provided by general hospitals; for Kersa, these are 


\section{Table 1. Kersa DSS Characteristics.}

\begin{tabular}{|c|c|c|c|c|c|c|c|c|c|c|c|c|}
\hline \multirow[t]{2}{*}{ Characteristics } & \multicolumn{12}{|l|}{ Year } \\
\hline & 2008 & 2009 & 2010 & 2011 & 2012 & 2013 & 2014 & 2015 & 2016 & 2017 & 2018 & 2019 \\
\hline Person-Year & 50,607 & 51,884 & 53,912 & 57,413 & 58,366 & 59,857 & 61,745 & 98,861 & 129,880 & 131,855 & 134,169 & 136,505 \\
\hline Total houses & 10,863 & 11,046 & 11,984 & 12,496 & 12,783 & 13,544 & 12,379 & 26,298 & 26,053 & 25,851 & 25,599 & 25,576 \\
\hline $\begin{array}{l}\text { Women (15-49 } \\
\text { yrs) \% }\end{array}$ & 21.96 & 22.15 & 22.29 & 22.85 & 22.96 & 23.24 & 23.33 & 22.79 & 22.62 & 22.77 & 22.29 & 22.70 \\
\hline Total live births & 1,604 & 1,771 & 1,996 & 1,571 & 1,801 & 2,327 & 2,212 & 3,100 & 3,803 & 4,427 & 4,482 & 3,665 \\
\hline $\begin{array}{l}\text { Crude birth rate } \\
\text { per } 1000\end{array}$ & 31.7 & 34.13 & 37.02 & 27.36 & 30.86 & 38.88 & 35.82 & 31.36 & 29.28 & 33.57 & 33.41 & 26.85 \\
\hline $\begin{array}{l}\text { Neonatal mortality } \\
\text { per } 1000 \text { live } \\
\text { births }\end{array}$ & 24.13 & 31.2 & 35.84 & 25.98 & 27.07 & 26.92 & 26.02 & 25.95 & 23.64 & 18.44 & 13.92 & 16.97 \\
\hline $\begin{array}{l}\text { Post-neonatal } \\
\text { mortality per } 1000 \\
\text { live births }\end{array}$ & 45.17 & 30.64 & 32.35 & 48.8 & 29.83 & 22.65 & 23.78 & 25.95 & 26.24 & 17.99 & 20.54 & 25.32 \\
\hline $\begin{array}{l}\text { Infant mortality } \\
\text { per } 1000 \text { live } \\
\text { births }\end{array}$ & 69.31 & 61.84 & 68.19 & 74.78 & 56.91 & 49.57 & 49.8 & 51.91 & 49.88 & 36.43 & 34.46 & 42.3 \\
\hline $\begin{array}{l}\text { Child mortality per } \\
1000 \text { population }\end{array}$ & 4.7 & 3.45 & 4.41 & 4.69 & 3.62 & 3.17 & 3.4 & 3.51 & 2.21 & 1.96 & 2.06 & 2.34 \\
\hline $\begin{array}{l}\text { Under-five } \\
\text { mortality per } 1000 \\
\text { live births }\end{array}$ & 147.28 & 99.72 & 118.47 & 170.47 & 116.57 & 81.2 & 94.21 & 111.18 & 74.56 & 57.53 & 60.97 & 85.94 \\
\hline Stillbirths & 9 & 10 & 6 & 4 & 6 & 10 & 8 & $61 *$ & 9 & 47 & $125^{\star}$ & 63 \\
\hline $\begin{array}{l}\text { Stillbirth per } 1000 \\
\text { births }\end{array}$ & 5.61 & 5.65 & 3.01 & 2.55 & 3.33 & 4.3 & 3.62 & 19.68 & 2.37 & 10.62 & 27.89 & 17.19 \\
\hline
\end{tabular}

Table 2. Harar HDSS Characteristics.

\begin{tabular}{|l|l|l|l|l|l|l|l|l|}
\hline Characteristics & $\mathbf{2 0 1 2}$ & $\mathbf{2 0 1 3}$ & $\mathbf{2 0 1 4}$ & $\mathbf{2 0 1 5}$ & $\mathbf{2 0 1 6}$ & $\mathbf{2 0 1 7}$ & $\mathbf{2 0 1 8}$ & $\mathbf{2 0 1 9}$ \\
\hline Person-Year & N/A & 31,099 & 31,579 & $\mathbf{4 3 , 3 1 4}$ & 58,706 & 57,983 & 57,719 & 58,095 \\
\hline Total houses & N/A & 8,823 & 8,836 & 16,654 & 16,129 & 16,104 & 15,579 & 15,299 \\
\hline Women (15-49 yrs) \% & N/A & 31.17 & 31.15 & 31.05 & 30.81 & 30.8 & 30.92 & 31.40 \\
\hline Total live births & N/A & 633 & 577 & 784 & 934 & 871 & 844 & 750 \\
\hline Crude birth rate per 1000 & N/A & 20.35 & 18.27 & 18.1 & 15.91 & 15.02 & 14.62 & 12.91 \\
\hline Neonatal mortality per 1000 live births & N/A & 4.74 & 3.47 & 7.65 & 3.21 & 5.74 & 1.18 & 1.33 \\
\hline Post-neonatal mortality per 1000 live births & N/A & 9.48 & 1.73 & 5.1 & 4.28 & 4.59 & 1.18 & 1.33 \\
\hline Infant mortality per 1000 live births & N/A & 14.22 & 5.2 & 12.76 & 7.49 & 10.33 & 2.37 & 2.67 \\
\hline Child mortality per 1000 population & N/A & 0.39 & 0.19 & 0.37 & 0.19 & 0.19 & 0.07 & 0.14 \\
\hline Under-five mortality per 1000 live births & N/A & 18.96 & 10.4 & 20.41 & 11.78 & 12.63 & 4.74 & 10.67 \\
\hline Stillbirths & N/A & N/A & N/A & N/A & 1 & 9 & 6 & 8 \\
\hline Stillbirth per 1000 births & N/A & N/A & N/A & N/A & 1.07 & 10.33 & 7.11 & 10.67 \\
\hline N/A: Not available & & & & & & & \\
\hline
\end{tabular}


Haramaya District Hospital and Haramaya University Hospital. From there patients can be referred to HFSUH in Harar or Dilchora Hospital in Dire Dawa. In 2015, HFSUH had its own laboratory on site, with microbiological capacity for urine and stool microscopy, molecular testing for TB (GeneXpert), and rapid tests for HIV. It also had a pathology laboratory, which had much of the equipment required to undertake CHAMPS but was in disrepair. There were teaching laboratories in the College of Health and Medical Sciences, but these had limited capacity for diagnostic tests. The regional laboratory for Harari region, also based in Harar, had capacity for more specialized tests, including HIV viral load testing and CD4 counts. The regional laboratory was and is coordinated by the national laboratory, based at the Ethiopian Public Health Institute.

\section{Developing capacity for CHAMPS}

In 2017, we established CHAMPS in Harar and Kersa, with site directors from LSHTM and HU to work in partnership. Together these directors identified investigators, recruited a project team and convened a national scientific advisory committee, chaired by the President of HU. The scientific advisory committee comprised members from our partners at the Ethiopian Public Health Institute, the Federal Ministry of Health, Armauer-Hansen Research Institute, the U.S. Centers for Disease Control and Prevention, London School of Hygiene $\&$ Tropical Medicine, and the Ethiopia office of BMGF.

Despite difficulties in attracting staff to an unknown project in a remote Ethiopian setting, we recruited a small number of international researchers to provide support in social science, paediatrics and microbiology. In addition, we employed national staff through HU. One of the challenges in this was the reluctance of skilled scientists to relocate to Harar. We developed project management support between LSHTM and HU, and established basic operations for communications, finance, human resource management and operational procedures for communication, procurement, transport, and security. These processes complemented and extended policies and procedures of $\mathrm{HU}$ and LSHTM. In our first year of initiation (2017-18) the site team grew rapidly to around 40 staff.

In parallel, we developed infrastructure at the site. At HU's College of Medical and Health Sciences, we restructured the hospital's pathology and university's microbiology laboratories; we also installed three septic tanks, a generator, two large water tanks and built an incinerator. We followed this with internal renovation and equipment installation, and we negotiated service contracts for five years where possible. We developed CHAMPS-specific specimen workflows and trained staff to ensure samples would be safely received, appropriately processed and securely stored. In the hospital we renovated rooms to perform MITS procedures and counsel families. We overhauled the mortuary to provide safe disposal of water and refrigeration to store the bodies of the deceased children and neonates. In addition, we arranged for repair and maintenance of basic clinical equipment such as patient scales or incubators to support inpatient care. We also strengthened collection and recording of routine clinical data, specifically in maternity and paediatrics. For our project team, we created office space through division of classrooms not in use at that time. We started to solve communication problems, which included intermittent and low-strength internet connection, and limited facilities for electronic data collection, data management and storage. We worked on these with the IT lead at the College of Health and Medical Sciences with additional expertise and advice from KEMRI-Wellcome Trust Research Programme, Kilifi, Kenya. We initiated infrastructure development and national applications for a satellite licence with a view to establishing a secure server room and a back-up satellite connection, as well as project-specific systems to support data collection, management and analysis which are now in place.

In Kersa HDSS we recruited staff and developed facilities. We trained two nurses in Kersa Health Centre on CHAMPS and identified 200 community members drawn from community extension workers, religious leaders, traditional birth attendants, local militia, "Qeerroo" (youth representing the Oromo movement in Ethiopia), other community leaders and HDSS data collectors or supervisors willing to be trained and support timely reporting of deaths. At Kersa Health Centre we built additional rooms for counselling, refrigeration of bodies and MITS. In due course similar facilities will be developed in a health centre in Water (also in Kersa District) and in Haramaya district Hospital.

Description of CHAMPS methods. We investigated child deaths using: (i) social science, to investigate community acceptability, practicality and feasibility of CHAMPS and its methods ${ }^{15,16}$, (ii) clinical surveillance, to support data capture, mortality notification and MITS, (iii) pathology, for histological assessment $^{17-19}$, (iv) microbiology ${ }^{20}$ to test samples using conventional microbiology, GenXpert and TaqMan Array Cards, and (v) verbal autopsy ${ }^{5,15-24}$. These data were analysed by an expert Determination of Cause of Death "DeCoDe" panel who assign a cause of death. Results will inform strategies to improve public health through a data-to-action plan ${ }^{21}$.

Social science work started first. We had recruited ten people to the social science team by May 2017. Following training, we undertook a Participatory Inquiry into Community Knowledge of Child Health and Mortality Prevention Surveillance (PICKCHAMPS, July-August 2017). This included 20 workshops in Kersa and Harar (437 participants) and aimed to: (i) develop a social history of the community and to hear about the ways in which the community had successfully met earlier challenges; (2) understand community perceptions, beliefs, and practices related to child death, CHAMPS activities, and the MITS procedure; and (3) build relationships and identify common ground with the community through ongoing, two-way communication. From this we developed a programme of community engagement, alongside formative research ${ }^{16}$. This helped to overcome fears about MITS in the community, for example beliefs that the procedure would lead to mutilation of the body or unacceptable delays in burial.

For mortality and clinical surveillance, we recruited doctors, nurses, public health officers, health assistants, field workers (FWs), and laboratory technicians, to set up and support 
structures for clinical data capture and mortality notification. These processes were initially developed in HFSUH in Harar, starting in the neonatal and maternity ward (in February 2019) with extension to the paediatric ward (in May 2019). The mortality surveillance established in HFSUH included a death notification system with initial notification of deaths by hospital staff to a central call centre. Following notification CHAMPS staff conducted an eligibility assessment, requested informed written consent from the legal guardians of the child, conducted tissue sampling via MITS, transport the body, and arrange follow-up (including verbal autopsy). Families received support and counselling from trained counsellors throughout the process. In Kersa (which started death notification and MITS in February 2019), mortality surveillance was conducted slightly differently. Death notification and eligibility assessment were undertaken by health care workers in Kersa Health Centre or by notifiers in the community, usually by telephone. Counselling and obtaining informed consent was led by a counsellor, together with members of the community MITS team, with community members usually joining this process. After obtaining formal written consent, and with consensus, the body was moved to Kersa for MITS, and the specimens taken to Harar for testing. Local pathways were developed for sample transport, sample processing in laboratories, and feedback of results, including notification of notifiable diseases to relevant authorities. The first DeCoDe panel ${ }^{21}$, set up to determine the cause of death with multidisciplinary expertise, was held on the $18-19^{\text {th }}$ September 2019.

Results from the DeCoDe panel aim to inform public health action - "data to action plans" which have been developed in partnership with the Ethiopian Public Health Institute and operate at subnational, national and international levels. The subnational plan includes sharing of results with families, the hospital, and community health care workers. To support policy-making at national level, we share aggregate data with the Ethiopian Public Health Institute and we plan to share non-aggregated data in the future. Internationally, data from Ethiopia are submitted in real time to the CHAMPS network database, which includes data from all sites.

CHAMPS - Ethiopia was approved in Ethiopia by the Institutional Health Research Ethics Review Committee (IHRERC) of the College of Health and Medical Sciences, Haramaya University (Ref: Dated 07/04/2017), and then nationally by the National Research Ethics Review Committee (NRERC) at the Ministry of Science and Technology (Ref: 3.10/70/2018), and the Armauer Hansen Research Institute (Ref: PO45/17). CHAMPS - Ethiopia was also approved by the London School of Hygiene \& Tropical Medicine, UK (Ref:14394). The overarching CHAMPS Network Data Analysis and Technical Support Protocol was approved by Emory Global Health Institute Review Board (IRB00091706), USA.

\section{Results}

By February 2020 we had received 1173 unique death notifications $\left(4^{\text {th }}\right.$ February $2019-3^{\text {rd }}$ February 2020),1043/1173 (89\%) from HFSUH and 880/1173 (75\%) from outside of the
HDSS catchment area. In the first year of surveillance, families for 59/99 of eligible cases gave consent for MITS (60\%) and were included. These included 24 stillbirths, 21 neonates and 14 infants or children ( $>28$ days to $<5$ years); 35 were from Harar and 24 from Kersa. Among the Kersa deaths, 14 died in the community and 10 died within a health facility. After assignment of cause of death from our expert panel, information was fed back to families, the hospital and community health care workers.

\section{Early learnings from the site}

We successfully implemented CHAMPS at a greenfield site, overcoming considerable challenges, and this process generated lessons for future greenfield site development. We based our assessment of potential sites largely on specific scientific criteria, and logistics in terms of travel and communications. We gave less consideration to security and staff living conditions, which, whilst they may not have ultimately influenced the choice of site, have presented us with considerable difficulties. A national state of emergency was declared repeatedly throughout 2016-2018 whilst we were initiating the programme. At these times, it was not always possible to travel or communicate effectively. Recruitment and retention challenges were thus considerably increased.

We recognised when initiating CHAMPS that success would need engagement and collaboration at all levels. Early engagement with national stakeholders, sustained through our scientific advisory committee, has given us political guidance and national support, helping us work at this level. For example, with religious community members, we approached the Ethiopian Islamic Affairs Supreme Council for a fatwah (a ruling on Islamic law) to conduct MITS on members of the Muslim community, which after careful consideration was granted and gave us permission to proceed with MITS activities in the study sites. Through our Community Advisory Boards (CABs) we have learned of, and addressed, specific issues in the community around body preparation and burial, providing opportunities for families to ensure religious practices are followed. To broaden engagement, we have broadcast a regular radio program, and invited community members to visit the research programme.

The large programme of community engagement resulted around in just under two thirds of those eligible providing consent for MITS and within this we recognised that consent was lower in Kersa than in Harar, potentially due to the need to transport bodies from Kersa to Harar for MITS at the start of recruitment. To mitigate this, we developed a facility to undertake MITS in Kersa Health Centre.

Substantial challenges remain. There is an understandable view from the community, that research should involve care for living children and those who are ill, rather than simply investigating those who have died. As a greenfield site, CHAMPS has been the focus of almost all our research work, and although study members have given support to the community where possible, for example in providing COVID testing, and 
giving clinical advice and health education sessions, we have not yet been able to initiate a significant research programme that investigates sick children, not just deceased children. This issue is an ongoing and major concern, and tackling it, by broadening the research work and securing funding to do this, is also vital for the long-term sustainability of the CHAMPS surveillance at the site.

\section{Conclusions}

CHAMPS is a complex multi-faceted project where each component must be executed to high standards to accomplish the whole. Achieving this goal in a new setting, at facilities with modest prior research experience and limited laboratory capacity, has been challenging. It has been made possible by the sustained investment of the funder, collaboration with the CHAMPS network, the determination of the investigating team, and the support of local, regional and national partners in Ethiopia. The project is now at a critical juncture. To sustain momentum, we need to develop young Ethiopian scientists who can carry the project forward over its anticipated 20-year life-span. We also need to broaden the research programme beyond post-mortem studies to tackle health research questions of local priority. This is essential to build understanding and acceptance among the community with whom we work and to attract and retain researchers who can generate the culture of scientific excellence required to sustain CHAMPS.

To tackle these challenges, we have established an overarching entity, the "Hararghe Health Research Partnership" which combines commitments from HU and LSHTM to generate a locally-relevant, sustainable programme of research centered around, but not restricted to, the CHAMPS project. The initial focus of this entity will be to improve health and reduce mortality in children and their mothers in a setting where health and child survival are currently poor. However, the underlying rationale for this entity is to achieve and sustain the ambitious goals of CHAMPS, through a self-sustaining research centre in an area of high disease burden that is able to address health issues of relevance locally, nationally and internationally.

\section{Data availability}

Underlying data

Summarized data are publicly available through the CHAMPS website https://champshealth.org/data/enrolled-populationsummary/. Requests for further detailed data, for research and evaluation purposes, can be made through https://champshealth. org/data/.

\section{Acknowledgements}

We would like to thank all those in the community and local administrations, who have supported and/or participated in the research to date. We also thank the National Scientific Advisory Committee, who have advised us on the development of CHAMPS in Ethiopia. We thank and acknowledge KEMRIWellcome Trust Research Programme, Kilifi, Kenya who have supported the programme, including sharing expertise and systems to support IT capability.
1. Liu L, Oza S, Hogan D, et al.: Global, regional, and national causes of under-5 mortality in 2000-15: an updated systematic analysis with implications for the Sustainable Development Goals. Lancet. 2016; 388(10063): 3027-35. PubMed Abstract | Publisher Full Text | Free Full Text

2. Saha SK, Schrag SJ, El Arifeen S, et al.: Causes and incidence of communityacquired serious infections among young children in south Asia (ANISA): an observational cohort study. Lancet. 2018; 392(10142): 145-59. PubMed Abstract | Publisher Full Text | Free Full Text

3. Kotloff KL, Nataro JP, Blackwelder WC, et al.: Burden and aetiology of diarrhoeal disease in infants and young children in developing countries (the Global Enteric Multicenter Study, GEMS): a prospective, case-control study, Lancet. 2013: 382(9888): 209-22. PubMed Abstract | Publisher Full Text

4. Ebruke BE, Knoll MD, Haddix M, et al.: The Aetiology of pneumonia from analysis of Lung aspirate and Pleural fluid samples: Findings from the PERCH study. Clin Infect Dis. 2020; ciaa1032. PubMed Abstract | Publisher Full Text

5. Raghunathan PL, Madhi SA, Breiman RF: Illuminating Child Mortality: Discovering Why Children Die. Clin Infect Dis. 2019; 69(Suppl 4): S257-S9. PubMed Abstract | Publisher Full Text | Free Full Text

6. The World Bank: Country Profile: Ethiopia. 2019; (accessed 22/6/2020). Reference Source

7. Ethiopian Public Health Institute Addis Ababa, Federal Ministry of Health Addis Ababa, The DHS Program ICF Rockville MU: Mini Demographic and Health Survey 2019. Mini Demographic and Health Survey 2019 (accessed 27/5/2020). Reference Source

8. Blencowe $\mathrm{H}$, Cousens $\mathrm{S}$, Jassir FB, et al.: National, regional, and worldwide estimates of stillbirth rates in 2015, with trends from 2000: a systematic analysis. Lancet Glob Health. 2016; 4(2): e98-e108. PubMed Abstract | Publisher Full Text

9. UNICEF: Levels and Trends in Child Mortality2012. (accessed 10.02.2013). Reference Source

10. Assefa N, Oljira L, Baraki N, et al.: HDSS Profile: The Kersa Health and Demographic Surveillance System. Int J Epidemiol. 2016; 45(1): 94-101. PubMed Abstract | Publisher Full Text | Free Full Text

11. Central Intelligence Agency. 2019; (accessed 19.12.2019). Reference Source

12. Assefa N, Lakew $\mathrm{Y}$, Belay B, et al.: Neonatal mortality and causes of death in Kersa Health and Demographic Surveillance System (Kersa HDSS), Ethiopia, 2008-2013. Matern Health Neonatol Perinatol. 2016; 2: 7. PubMed Abstract | Publisher Full Text | Free Full Text

13. Dedefo $M$, Zelalem D, Eskinder $B$, et al.: Causes of Death among Children Aged 5 to 14 Years Old from 2008 to 2013 in Kersa Health and Demographic Surveillance System (Kersa HDSS), Ethiopia. PLoS One. 2016; 11(6): e0151929. PubMed Abstract | Publisher Full Text | Free Full Text

14. Assefa Y, Gelaw YA, Hill PS, et al.: Community health extension program of Ethiopia, 2003-2018: successes and challenges toward universal coverage for primary healthcare services. Global Health. 2019; 15(1): 24. PubMed Abstract | Publisher Full Text | Free Full Text

15. Blevins J, O'Mara Sage E, Kone A, et al: Using Participatory Workshops to Assess Alignment or Tension in the Community for Minimally Invasive Tissue Sampling Prior to Start of Child Mortality Surveillance: Lessons From 5 Sites Across the CHAMPS Network. Clin Infect Dis. 2019; 69(Suppl 4): S280-S90.

PubMed Abstract | Publisher Full Text | Free Full Text

16. O'Mara Sage E, Munguambe KR, Blevins J, et al.: Investigating the Feasibility 
of Child Mortality Surveillance With Postmortem Tissue Sampling: Generating Constructs and Variables to Strengthen Validity and Reliability in Qualitative Research. Clin Infect Dis. 2019; 69(Suppl 4): S291-S301. PubMed Abstract | Publisher Full Text | Free Full Text

17. Chawana R, Baillie V, Izu A, et al.: Potential of Minimally Invasive Tissue Sampling for Attributing Specific Causes of Childhood Deaths in South Africa: A Pilot, Epidemiological Study. Clin Infect Dis. 2019; 69(Suppl 4): S361-S73.

PubMed Abstract | Publisher Full Text | Free Full Text

18. Madhi SA, Pathirana J, Baillie V, et al.: Unraveling Specific Causes of Neonata Mortality Using Minimally Invasive Tissue Sampling: An Observational Study. Clin Infect Dis. 2019; 69(Suppl 4): S351-S60. PubMed Abstract | Publisher Full Text | Free Full Text

19. Madhi SA, Pathirana J, Baillie V, et al.: An Observational Pilot Study Evaluating the Utility of Minimally Invasive Tissue Sampling to Determine the Cause of Stillbirths in South African Women. Clin Infect Dis. 2019; 69(Suppl 4): S342-S50.

PubMed Abstract | Publisher Full Text | Free Full Text

20. Diaz MH, Waller JL, Theodore MJ, et al.: Development and Implementation of Multiplex TaqMan Array Cards for Specimen Testing at Child Health and
Mortality Prevention Surveillance Site Laboratories. Clin Infect Dis. 2019; 69(Suppl 4): S311-S21.

PubMed Abstract | Publisher Full Text | Free Full Text

21. Blau DM, Caneer JP, Philipsborn RP, et al.: Overview and Development of the Child Health and Mortality Prevention Surveillance Determination of Cause of Death (DeCoDe) Process and DeCoDe Diagnosis Standards. Clin Infect Dis. 2019; 69(Suppl 4): S333-S41. PubMed Abstract | Publisher Full Text | Free Full Text

22. Cunningham SA, Shaikh NI, Nhacolo A, et al:: Health and Demographic Surveillance Systems Within the Child Health and Mortality Prevention Surveillance Network. Clin Infect Dis. 2019; 69(Suppl 4): S274-S9. PubMed Abstract | Publisher Full Text | Free Full Text

23. Gudata ZG, Cochrane L, Imana G: An assessment of khat consumption habit and its linkage to household economies and work culture: The case of Harar city. PLoS One. 2019; 14(11): e0224606. PubMed Abstract | Publisher Full Text | Free Full Text

24. Salzberg NT, Sivalogan K, Bassat Q, et al.: Mortality Surveillance Methods to Identify and Characterize Deaths in Child Health and Mortality Prevention Surveillance Network Sites. Clin Infect Dis. 2019; 69(Suppl 4): S262-S73. PubMed Abstract | Publisher Full Text | Free Full Text 


\title{
Open Peer Review
}

\section{Current Peer Review Status:}

Version 1

Reviewer Report 23 December 2021

https://doi.org/10.21956/gatesopenres.14646.r31493

(C) 2021 Lindtjørn B. This is an open access peer review report distributed under the terms of the Creative Commons Attribution License, which permits unrestricted use, distribution, and reproduction in any medium, provided the original work is properly cited.

\author{
Bernt Lindtjørn \\ ${ }^{1}$ School of Public and Environmental Health, Hawassa University, Hawassa, Ethiopia \\ ${ }^{2}$ Centre for International Health, University of Bergen, Bergen, Norway
}

This paper is an overview of the background and start of important research in eastern Ethiopia. The project is called the Child Health and Mortality Prevention Surveillance (CHAMPS) network and aims to ascertain causes of child death in the high child mortality setting. The study is a collaboration between the Haramaya University and the London School of Hygiene and Tropical Medicine and builds on the previously established Kersa demographic surveillance site, which has also been expanded to include urban areas.

I have read and reviewed several of the publications from this demographic site during the past years. A weakness I recently found, is that the number of events such as births and deaths occurring over the years differ in the various publications and submitted papers I have read or reviewed. I, therefore, question the validity of the database of the actual demographic site that they use. To get sound data, this demographic site should authenticate their database so that they don't produce conflicting results. Similar problems have in the past occurred with other demographic sites in Ethiopia, and they needed to do comprehensive audits to establish the most probable and valid data.

The authors explain why they selected the studies site. The size of the study population seems to have been a factor in this decision. Nevertheless, a weakness of their study site selection is described in this paper as they were not allowed to do autopsies on many of the children who died. The authors ascribe this to the society being predominantly Muslim, and they also describe ways that they try to mitigate this challenge. However, the Harar area is an old and traditional society following strict Muslim faith, and the organisers of this study should have known that this would bring about a selection bias of their study, which makes the findings from this particular area not generalisable to other parts of Ethiopia. But it would be relevant for the eastern parts of the country.

The aim of the project is to develop a programme for monitoring causes of child deaths in 
Ethiopia. The project plans to last at least 20 years. It is, therefore, surprising that the study doesn't highlight the need to have Ethiopian scientists as leaders of this project right from the start. I mention this controversial issue because the paper states that the implementation was delayed because the project was not capable of recruiting adequately trained personnel to do the tasks. Having many years of working experience in Ethiopia and having evaluated many foreign supported health and research projects, it is important to recognize that sustainability in Ethiopia can only be achieved if the leadership and the management of the project are done by the Ethiopians themselves. In my experience, it is possible to get trained personnel from the country and regions or educate personnel to do necessary tasks. Expatriate personnel can serve in supportive functions.

The programme seemed to have had delays and interruptions due to the social unrest that has occurred in the country the past four to five years. In my experience over the last 45 years, it is most important that projects are not dependent on the presence of expatriates to run projects. I have not experienced projects stop more than a few weeks because of social unrest or civil war when the leadership is national. And - that is another reason to re-evaluate the ownership and leadership model of this project.

Is the work clearly and accurately presented and does it cite the current literature? Yes

Is the study design appropriate and is the work technically sound? Partly

Are sufficient details of methods and analysis provided to allow replication by others? Partly

If applicable, is the statistical analysis and its interpretation appropriate? Not applicable

Are all the source data underlying the results available to ensure full reproducibility? Partly

Are the conclusions drawn adequately supported by the results? Partly

Competing Interests: No competing interests were disclosed.

Reviewer Expertise: Global health, long experience working in Ethiopia

I confirm that I have read this submission and believe that I have an appropriate level of expertise to confirm that it is of an acceptable scientific standard, however I have significant reservations, as outlined above.

Author Response 09 Feb 2022

Anna Seale, 
Thank you for your review.

We agree consistency in outputs in Health and Demographic Surveillance Sites is critical, and that authentication of databases is important. Over the years the processes in place at Kersa, and then Harar, HDSS have evolved. We have noted now in the paper that through joining the network of sites there is a review of data cleaning, data locking and data extraction, which should result in more consistent application of the data.

"There have been, and are, data quality checks throughout the surveillance process in the HDSS. In addition, joining a network of sites with demographic surveillance is providing the opportunity to review standard operating procedures for data cleaning, data locking and data extraction, which should result in more consistent application of the data."

In selecting the site, we recognised that the strong culture and religious beliefs in this part of Ethiopia presented a challenge to the project. Overall, whilst a challenge, and differing to some other parts of Ethiopia, it was important to look to include data from where it was least available, and where child mortality appeared very high; this was the case in this site. In selection we noted that CHAMPS was initiated in other regions where Islamic faith was predominant, such as Bangladesh, and in developing the site we used learning from Bangladesh to inform our approach. We have edited the text to reflect that this point was a challenge, noted on selection, and later in the results.

"Finally, whilst recognising that there would be challenges to working in this area, with its strong history, culture and religions, Kersa/Harar was selected and confirmed as the most suitable location."

"Working in this area, with its strong culture, history and religious identity has brought challenge, but a key part of developing such a CHAMPS site was to do so in a high-mortality setting - where data are usually most limited. Whilst the identity of the region differs to others in Ethiopia, which has very distinctive regions, findings will be able to be compared to other CHAMPS sites, and their generalisability assessed."

We agree that having Ethiopian scientists as leaders of the project from the start was, and is, critical. From the outset we sought out national engagement, contributing, for example, to site selection. We have also had joint leadership, working in partnership. However, as we highlight in our conclusion, there is an ongoing need to develop new research leaders, and hence the formalisation of the "Hararghe Health Research Partnership" with exactly this aim, to develop a critical mass of research leaders for the future. This has already been able to attract external funding for a cohort of PhD students, the first of which started this year. We have edited the text to highlight the need for in-country leadership, in several places in the abstract, text and in the conclusion, "However, the underlying rationale for this entity is to achieve and sustain the ambitious goals of CHAMPS, through a self-sustaining research centre, with in-country technical expertise and leadership, in an area of high disease burden that is able to address health issues of relevance locally, nationally and internationally."

Our comment on recruitment related both to international staff (of which we had four in this period) as well as national staff (around forty in the same period), and the challenges to recruitment were increased through security concerns for all staff. Disruption also arose from associated interruptions to communications and essential services for prolonged 
periods. We have clarified that challenges were experienced by all staff, "Despite difficulties in attracting staff to an unknown project in a remote Ethiopian setting, we recruited a small number of international researchers to provide expert technical support in social science, paediatrics, and microbiology to initiate the project, working alongside national staff, employed through $\mathrm{HU}$, sharing learning as the project developed. One of the challenges in this was the reluctance of skilled scientists (both national and international) to relocate to Harar."

Competing Interests: No competing interests were disclosed.

Reviewer Report 14 December 2021

https://doi.org/10.21956/gatesopenres.14646.r31495

(C) 2021 Bigogo G. This is an open access peer review report distributed under the terms of the Creative Commons Attribution License, which permits unrestricted use, distribution, and reproduction in any medium, provided the original work is properly cited.

\section{Godfrey M. Bigogo}

Center for Global Health Research, Kenya Medical Research Institute, Kisumu, Kenya

The article describes the processes and experiences encountered by the authors in their quest to set up a CHAMPS site in a "greenfield" in Ethiopia. It is noteworthy that Ethiopia has experienced some political instability over time, but this did not deter the investigators in their pursuit of establishing a site that would provide answers to the causes of child deaths in the area. Kersa, one of the sites described in the paper, is primarily rural with inadequate water, electricity and communication infrastructure. Such settings often have high morbidity and mortality burden, but are often shunned by investigators because of the potential difficulties in settling and working in these areas. The investigators should be commended for facing this challenge head-on.

Overall, the manuscript is written very well. A few points that the authors may clarify:

1. The authors report that by February 2020, they had received 1173 unique death notifications. However only 99 MITS had been conducted and only 59 investigated to determine cause of death. What is the primary cause of the disparity between the number of deaths notified and MITS done? It is possible that some notification may be ineligible but presumably those would be a small fraction.

2. Please provide a population density estimate for Harar (as done for Kersa) for ease of comparison, if available.

Is the work clearly and accurately presented and does it cite the current literature? Yes

Is the study design appropriate and is the work technically sound? Yes 
Are sufficient details of methods and analysis provided to allow replication by others? Partly

If applicable, is the statistical analysis and its interpretation appropriate?

Not applicable

Are all the source data underlying the results available to ensure full reproducibility?

Yes

Are the conclusions drawn adequately supported by the results?

Yes

Competing Interests: No competing interests were disclosed.

Reviewer Expertise: Infectious disease surveillance, and demography

I confirm that I have read this submission and believe that I have an appropriate level of expertise to confirm that it is of an acceptable scientific standard.

Author Response 09 Feb 2022

Anna Seale,

Thank you for your review.

With respect to the disparity between the number of death notifications and MITS done, we have clarified that whilst there were 1173 unique death notifications, many of these (880) were outside the area of demographic surveillance, and therefore not eligible for inclusion. "By February 2020 we had received 1173 unique death notifications (4 ${ }^{\text {th }}$ February $2019-3^{\text {rd }}$ February 2020), 1043/1173 (89\%) from HFSUH. There were 880/1173 (75\%) notifications from outside of the HDSS catchment area, who were not eligible to include. After assessment against other criteria (such as time since death), of the 293 notifications within the HDSS catchment area, there were 99 eligible deaths in the first year of surveillance. Families for 59/99 of eligible cases gave consent for MITS (60\%) and were included."

We have added the population density for Harar to the site description, which is 2234 people/km².

Competing Interests: No competing interests were disclosed. 